\title{
ПЕРИОДИЧЕСКАЯ ГИПЕРСОМНИЯ (СИНДРОМ КЛЕЙНА-ЛЕВИНА) - СЛУЧАЙ ИЗ КЛИНИКИ
}

\author{
${ }^{1}$ Н.А.Алиев, ${ }^{2}$ З.Н.Алиев, ${ }^{3}$ С.Э.Алиева \\ ${ }^{1}$ Азербайджанский Государственный Институт Усовершенствования Врачей им. Азиза Алиева, \\ кафедра психиатрии и наркологии, Баку; \\ ${ }^{2}$ Кафедра психиатрии Азербайджанского Медииинского Университета, Баку; \\ ${ }^{3}$ Детская Неврологическая Больница, Баку
}

$\mathbf{C}$ он можно определить как регулярно повторяющееся, легко обратимое состояние организма, которое характеризуется относительным покоем, а также значительным повышением порога реакций на внешние стимулы по сравнению с состоянием бодрствования. Жалобы на расстройство сна составляют основную часть всех жалоб. Контроль над состоянием сна играет важную роль в клинической практике, поскольку нарушения сна являются ранним признаком начинающегося психического заболевания. Недавно проведенные исследования в области сна показали, что некоторые психические расстройства связаны с характерными изменениями физиологии сна. Эти изменения позволяют понять психофизиологические особенности, лежащие в основе психических расстройств, а также поставить диагноз на основании комплекса клинических проявлений. Синдром Клейна-Левина (также известный как Клейна-Левина-Критчли и синдром "Спящей красавицы") относится к периодически наблюдающимся расстройствам в виде повышенной сонливости. Этот синдром был впервые описан в 1786 году французским врачом, который специализировался по женским заболеваниям [5].

Этимология: он назван в честь Willi Kleine и Max Levin. [10,14]. Willi Kleine (KLS) описал ceрию из девяти случаев с периодической сонливостью в 1925 году. В 1936 году Max Levin (который родился в России и проживал в США) добавил серию больных из пяти случаев, уделяя особое внимание взаимосвязи между сонливостью и нарушением питания. В 1962 году Critchley [5], который дал расстройству свое название, добавил 11 случаев, которые он лично наблюдал как врач британского королевского флота. В недавнем обзоре литературы,. Arnulf et al, [2] составлено 186 случаев, начиная с 1962 *e-mail: zafar535@gmail.com

по 2004 год. Huang и Arnulf в своих работах показали клинику синдрома Клейна-Левина [8], описанный Brierre de Boismont [3].

Синдром Клейна-Левина является относительно редким синдромом, состоящим из периодов чрезмерно длительного сна (от которых больной может пробуждаться), чередующихся с периодами нормального сна и бодрствования. Во время эпизодов гиперсомнии периоды бодрствования обычно характеризуются социальной изоляцией больного и его стремлением лечь в постель при первой же возможности; однако у больных могут также быть апатия, раздражительность, спутанность сознания, неумеренность в еде, сексуальная расторможенность, бред и галлюцинации, дезориентировка, нарушения памяти, бессвязная речь, возбуждение или депрессия и грубое поведение. У некоторых больных появляется необъяснимая лихорадка.

Синдром Клейна-Левина встречается относительно редко, хотя его распространенность не достаточно изучена. Зарегистрировано около 200 случаев, характеризующихся чертами, позволяющими предполагать этот диагноз. В большинстве случаев некоторые периоды гиперсомнии, каждый из которых продолжается одну или несколько недель, наблюдаются у больного в течение года. За некоторыми исключениями, первый приступ появляется в возрасте между 10 и 21 годами. В редких случаях состояние возникает на четвертом и пятом десятке жизни. Расстройство протекает почти всегда изолированно, с ремиссией, возникающей спонтанно в возрасте до 40 лет в случаях с ранним началом. Недавно описан случай синдром Клейна-Левина у 86-летного старика.

Причины. Некоторые исследователи утверждают, что может быть наследственная предрасположенность, другие считают, что 
может быть результатом аутоиммунных расстройств [11]. И наконец, третьи считают, что синдром Клейна-Левина может быть связан с поражением гипоталамуса, который регулирует такие функции, как сон, аппетит, и температура тела [16]. Последние исследования также показывают, что причиной может быть дефицит концентрации транспортера дофамина в нижнем стриатуме [7].

Демография. Изучение 108 пациентов с синдромом Клейна-Левина показало, что большинство случаев наблюдались у юношей со средним соотношением полов $3: 1$. Средний возраст начала был 15,7 лет, 81,7\% переживали первый эпизод от 10 до 20 лет. Возраст первого эпизода колебался от 6 до 59 лет. Среди населения США, представляет в KLS кавказцев в три раза больше ожидаемые частоты, и в шесть раз превышает ожидаемые частоты среды еврейского населения [1].

Симптомы. Список признаков и симптомов упоминается в различных источниках. Синдром Клейна-Левина включает в себя, ниже перечисленные симптомы: 1. Сонливость; 2. Мегафагия; 3. Гиперсексуальность; 4. Нарушение поведения; 5. Раздражительность; 6. Бессвязная речь; 7. Галлюцинации; 8. Чрезмерная потребность во сне; 9. Недостаток энергии; 10. Повышенная чувствительность к шуму; 11. Дезориентация; 12. В самом начале эпизода пациент становится сонным и спит большую часть дня и ночи (гиперсомнолентность), просыпаясь только поесть или сходить в туалет; 13. Когда они просыпаются, их поведение изменяется, и внешне часто напоминает "чудного" ребенка; 14. Проснувшись, они испытывают спутанность сознания, дезориентацию, полное отсутствие энергии (вялость), а также отсутствие эмоций (апатия); 15. Часто лица не могут посещать школу, работу или не могут ухаживать за собой. Большинство из этих больных много времени проводят постели.

Гиперсомния является основным симптомом синдрома Клейна-Левина. Часто первоначально их лечили в связи с расстройствами сна. В эпизоде синдрома Клейна-Левина в сутки пациенты зачастую тратили на сон 18 часов. Другой отличительный симптом синдро- ма Клейна-Левина это изменение психического состояния в течение эпизода. Субъектам трудно было просыпаться, они становились раздражительными или агрессивными при попытке не позволять спать. Также объективно часто наблюдались когнитивные нарушения [13], среди которых можно указать спутанность, амнезию на период события, галлюцинации, бред или опыт сноподобных состояний в прошлом. Около 75\% пациентов с синдромом Клейна-Левина наблюдались изменения пищевого поведения во время эпизодов, причем большинство этих явлений были представлены мегафагией. Данные показывали, что пациенты ели все, что им попадалось, т.е. избирательность в еде была очень мала. Почти у половины пациентов с синдромом Клейна-Левина наблюдалось гиперсексуальное поведение, в том числе распущенность, чрезмерная мастурбация, неуместные сексуальные домогательства. Гиперсексуальное поведение чаще встречается у мужчин, чем у женщин и ассоциируется намного дольше с этим заболеванием [18]. Другие необычные формы поведения тоже не являются редкостью [9].

Диагностика. Диагностика KLS очень трудна, поскольку нет никаких признаков, которые бы приняли в расчет для положительного диагноза. Для диагностики KLS методом исключения, врач должен сначала устранить длинный список других условий, которые могут имитировать эти симптомы. Потому что сонливость является основным симптомом у многих пациентов. Потенциальных пациентов KLS часто направляют к эндокринологу на раннем этапе для проверки метаболических проблем, включая диабет и гипотиреоз. Но многие симптомы могут быть позитивно диагностированы с помощью МРТ, обусловленные повреждением, опухолью или воспалением. Рассеянный склероз также имеет неврологические составляющие, которые могут имитировать симптом, характерный для KLS.

Людям с KLS зачастую ошибочно ставят диагноз психического расстройства. Периоды сомноленции, гиперфагии и отсутствия могут имитировать тяжелую депрессию, не- 
которые пациенты испытывают короткие периоды повышенной энергии во время этого состояния, похожие на маниакальный эпизод, так что некоторым пациентам ошибочно диагностировали биполярное расстройство. Также может быть ряд других симптомов расстройств настроения и восприятия, которые имитировали первично психическое расстройство KLS. До постановки окончательного диагноза должны быть полностью исключены все возможности и группа симптомов должна соответствовать тем, которые встречаются у больных KLS [6].

Лечение. Окончательное лечение синдрома Клейна-Левина отсутствует. В настоящее время в лечении синдрома Клейна-Левина используются в основном психостимуляторы, такие как амфетамины, метилфенидат и модафинил и др. [12].

Есть некоторое сходство между синдромом Клейна-Левина и биполярным расстройством, и литий, и карбамазепин. Как сообщается, эти препараты в некоторых случаях сокращает продолжительности эпизодов. Ответ на лечение часто носит ограниченный характер. Это расстройство необходимо отличать от циклических повторных появлений сонливости во время предменструального периода у девочекподростков, которые могут управляться при помощи гормональной контрацепции [15].

Частота и продолжительность эпизодов. Изучение 168 пациентов с KLS, что средний возраст составляет 23 и средняя продолжительность болезни примерно составляет 4 года. Сообщается об отсутствии корреляции между возрастом начала и длительностью заболевания. Пациенты испытывали в среднем 12 эпизодов, продолжавшиеся в среднем 12 дней, хотя пределы симптомов в сообщении варьировали от 2-130 эпизодов и продолжались между 2,5 и 80 днями. Средняя продолжительность между эпизодами была 6 месяцев, но колебалась от 0,5 до 72 месяцев. Субъекты типично испытывали атаки меньшей частоты и интенсивности к концу заболевания. Больной считался вылеченным, если он не имел эпизода в течение 6 месяцев. Средняя продолжительность болезни составляет 10 лет у пациентов без гиперсексуальности, но 21 год у пациентов с гиперсексуальностью [2].

Прогноз. Качество жизни больных с KLS очень серьезно снижено. Многие пациенты испытывают депрессию в течение одного или нескольких эпизодов. В то время как основные симптомы могут показаться достаточными, (большое количество сна, еды, а также сексуальное поведение), эффекты могут быть очень слабыми. По крайней мере, KLS затрудняет поддержание нормальной работы, а в некоторых случаях становится причиной уголовных обвинений в безудержном сексуальном поведении. Периодические гиперсомнические эпизоды часто приводят к увеличению веса. Пациенты, страдающие синдромом Клейна-Левина, в конечном итоге, страдают от других психосоциальных стигм, поскольку они не понимают некоторые результаты в течение эпизода. Многие пациенты страдали KLS с раннего подросткового возраста [17].

Во многих случаях, расстройство исчезает так же таинственно, как и появляется, часто, когда пациенты достигают двадцатилетнего возраста.

Тяжесть гиперсомнии помешала ему принять участие в школьных мероприятиях. Вне эпизода чрезмерного сна у Д.В. никаких нарушений со стороны психики, в том числе, когнитивные и поведенческие расстройства не наблюдались. Каждый раз во время сна наблюдалась мегафагия или гиперфагия (чрезмерное употребление пищи) и гиперсексуальность. Несмотря на многочисленные обращения к врачам, улучшение в состоянии больного не наблюдалось. Лабораторные анализы (анализ крови, мочи, кала, гормональные, биохимические и другие исследования) были в пределах нормы. Компьютерная и магнитно-резонансная томография головного мозга без патологии. ЭЭГ была характерна для ночного сна. В июне 2010 года автором этой статьи было назначено следующее лечение: 1. Лития карбонат 300 мг 2 раза в день. 2. Мелипрамин 25 мг 3 раза в день внутрь. 3. Тегретол 0,2 мг 3 раза в день. С этого времени эпизоды гиперсомнии отсутствуют. По сей день, эпизоды гиперсомнии больше не повторялись. 


\section{Периодичность и длительность приступов синдрома Клейна-Левина1 у Д.В. (с интервалом от 10 до 40 дней)}

\begin{tabular}{|c|c|c|c|c|}
\hline \multirow[t]{2}{*}{ Год } & \multirow[t]{2}{*}{ Месяц } & \multicolumn{3}{|l|}{ Декада } \\
\hline & & 1 & 2 & 3 \\
\hline 2008 & Декабрь & $* * * * * * * * * * * *$ & & \\
\hline \multirow[t]{12}{*}{2009} & Январь & & & \\
\hline & Февраль & & $* * * * * * * * * * * *$ & \\
\hline & Март & $* * * * * * * * * * * *$ & & \\
\hline & Апрель & & & $* * * * * * * * * * * *$ \\
\hline & Май & $* * * * * * * * * * * *$ & & \\
\hline & Июнь & & $* * * * * * * * * * * *$ & \\
\hline & Июль & $* * * * * * * * * * * *$ & & \\
\hline & Август & & & ************* \\
\hline & Сентябрь & & $* * * * * * * * * * * *$ & \\
\hline & Октябрь & & $* * * * * * * * * * * *$ & \\
\hline & Ноябрь & $* * * * * * * * * * * *$ & & \\
\hline & Декабрь & $* * * * * * * * * * * *$ & & \\
\hline \multirow[t]{6}{*}{2010} & Январь & $* * * * * * * * * * * *$ & & \\
\hline & Февраль & & $* * * * * * * * * * * *$ & \\
\hline & Март & $* * * * * * * * * * * *$ & & \\
\hline & Апрель & & $* * * * * * * * * * * *$ & \\
\hline & Май & & $* * * * * * * * * * * *$ & \\
\hline & Июнь & \multicolumn{3}{|c|}{$\begin{array}{l}\text { Начато лечение (Lithium carbonate, Melipramin, Tegretol). Катамне- } \\
\text { стические данные показали, что с начала терапии, т.е. с июня } 2010 \\
\text { года по июнь } 2013 \text { года эпизоды гиперсомнии отсутствуют }\end{array}$} \\
\hline
\end{tabular}

\section{Примечание:}

1Код по международной классификации расстройств сна 780.54-2 - Периодическая гиперсомния (Синдром Клейна-Левина). Код по международной классификации болезней 10 пересмотра G 47.8 - Другие нарушения сна (Синдром Клейна-Левина).

*В рисунке указано повторение эпизодов гиперсомнии при синдроме Клейна-Левина в течение 19 месяцев.

\section{ЛИТЕРАТУРА}

1. Arnulf I., L. Lin, N. Gadoth, J. File, M. Lecendreux, P. Franco, J. Zeitzer, B. Lo, J. H. Faraco, E. Mignot. KleineLevin syndrome: a systematic study of 108 patients. Ann Neurol, 2008 Apr; 63(4): 482-493.

2. Arnulf I., J. M. Zeitzer, J. File, N. Farber, E. Mignot. Kleine-Levin syndrome: A systematic review of 186 cases in the literature. Brain, 2005 Dec; 128(Pt 12): 2763-2776.

3. Brierre de Boismont A. Des hallucinations. Third edition. Germer Baill?re Ed, Paris 1862. pp 339-40.

4. Chauvot de Beauch?ne: E. P. Observation sur une maladie nerveuse. Avec complication d'un sommeil tant?t lethargique, tant?t convulsif. A Amsterdam et ? Paris: chez M?quignon l'aine, 1786. [Observation of a nervous disease attended by disturped sleep, at times lethargic and at times convulsive.]

5. Critchley M.: Periodic hypersomnia and megaphagia in adolescent males. Brain, Oxford, 1962, 85: 627-656.

6. Fisher W. M.MD. Telephone INTERVIEW. 6 Nov, 2008.

7. Hoexter M. Q., M. C. Shih, D. D. Mendes, C. Godeiro-
Junior, A. C. Felicio, Y. K. Fu, S. Tufik, R. A. Bressan. Lower dopamine transporter density in an asymptomatic patient with Kleine-Levin syndrome. Acta Neurol Scand, 2008, May, 117(5): 370-373.

8. Huang, Y. S. I. Arnulf I.: The Kleine-Levin syndrome. Sleep Medicine Clinics, 2006, 1: 89-103.

9. Justo L. P., H. M. Calil, S. A. Prado-Bolognani, M. Muszkat. Kleine-Levin syndrome: Interface between neurology and psychiatry. Arq Neuropsiquiatr, 2007, Mar, 65(1): 150-152.

10. Kleine W.: Periodische Schlafsucht. Monatsschrift f?r Psychiatrie und Neurologie, 1925, 57: 285-320.

11. Kleine-Levin syndrome - Center for Narcolepsy Stanford University School of Medicine.

12. Kleine-Levin Syndrome Information Page: National Institute of Neurological Disorders and Stroke (NINDS) . 13. Landtblom A. M., N. Dige, K. Schwerdt, P. S?fstr?m, G. Gran?rus. Short-term memory dysfunction in KleineLevin syndrome. Acta Neurol Scand, 2003, Nov, 108(5): 363-367. 
14. Levin M.: Periodic somnolence and morbid hunger: A new syndrome. Brain, Oxford, 1936, 59: 494-504.

15. Muratori F., N. Bertini, G. Masi. Efficacy of lithium treatment in Kleine-Levin syndrome. Eur Psychiatry, 2002, Jul, 17(4): 232-233.

15. Poryazova R., B. Schnepf, P. Boesiger, C. L. Bassetti.
Magnetic resonance spectroscopy in a patient with KleineLevin syndrome. J Neurol, 2007, Oct, 254(10): 1445-1446. 16. Schenck C. H., I. Arnulf, M. W. Mahowald. Sleep and sex: What can go wrong? A review of the literature on sleep related disorders and abnormal sexual behaviors and experiences. Sleep, 2007, Jun 1, 30(6): 683-702.

\title{
XÜLASə
}

\section{PERIODIKK HIPPERSOMNIYA (KLEYN-LEVIN SİNDROMU) - KLINIIKI HADISO}

\author{
N.A. Oliyev ${ }^{1}$, Z.N.Oliyev², S.E.Oliyeva ${ }^{3}$ \\ ${ }^{`}$ O. Oliyev ad. Azərbaycan Dövlət Həkimləri Təkmilləşdirmə Institutu, Psixiatriya və narkologiya ka- \\ fedrast, Bakl; \\ ${ }^{2}$ Azarbaycan Tibb Universiteti, Psixiatriya kafedrası, Bakı; \\ ${ }^{3}$ Uşaq nevroloji xəstəxanasi, Bakı
}

1992-ci il təvəllüdlü xəstə D.V. fəhlə ailəsində vaxtında doğulmuşdur. Özündən iki yaş kiçik bacısı vardır. Anamnezindən məlumdur ki, bir yaşında sarılıq xəstəliyi keçirmişdir. Başqa xəstəlikləri və baş travmasını inkar edir. Xəstəlik ilk dəfə 2008-ci ildə (yəni 16 yaşında) məktəbdə ədəbiyyat dərsi zamanı başlanmışdır. Müəllimə bütün şagirdlərə, o cümlədən də D.V.-yə yoxlama işi yazmağı təklif etmişdir. Müəllimənin bu təklifi onda güclü reaksiyaya səbəb olmuş və o, kontrol işi yazmaqdan imtina edərək, müəlliməni nalayiq sözlərlə təhqir etmiş, icazəsiz dərsi tərk etmişdir. Müəllimə ilk dəfə şagirddə bu vəziyyəti görərək onun sağlamlığına şübhə ilə yanaşmış və başqa bir şagirdə göstəriş vermişdir ki, D.V.-ni evlərinə qədər müşayiət etsin. D.V. evə gələn kimi yatağa uzanıb 10 gün fasiləsiz yatmışdır. Fizioloji tələbatlarını yerinə yetirmək və qida qəbulu üçün arabir yuxudan ayılırmış. Xəstədə bu vəziyyət hər 30-40 gündən bir təkrarlanaraq, fasiləsiz 10 gün yuxu ilə müşahidə olunmuşdur. Qidanı xüsusi acgözlüklə (meqafaqiya) qəbul etmişdir. Bu zaman xəstədə cinsi hissiyyatın yüksəlməsi (hiperseksuallıq) ilə bərabər, ətrafdakılara qarşı kobudluq, utanmamazlıq nümayiş etdirmişdir. Həkimlərə çox saylı müraciətlərə baxmayaraq xəstənin vəziyyətində heç bir yaxşılaşma qeydə alınmamışdır. Laboratoriya analizləri və baş beynin maqnit-rezonans tomoqrafiyası norma daxilində olmuşdur. EEQ gecə yuxusuna xarakter olmuşdur.

\section{SUMMARY}

\section{PERIODIC HYPERSOMNIA (KLEINE-LEVIN SYNDROME) - CLINICAL CASE}

\author{
N.A.Aliyev ${ }^{1}$, Z.N.Aliyev², S.E.Aliyeva ${ }^{3}$ \\ ${ }^{1}$ Azerbaijan State Advanced Training Institute for Doctors named after A.Aliyev, Department of psy- \\ chiatry and narcology, Baku; \\ ${ }^{2}$ Azerbaijan Medical University, Department of psychiatry, Baku; \\ ${ }^{3}$ Child Neurology Hospital, Baku
}

Annotation - A 18 year-old boy presented with excessive sleepiness was begging in 15 year-old. Diseases for the first time have begun 2008 during a lesson under the literature. Patient continuously have slept for 10 days. From time to time it was overslept only for food intake and on physiological needs. During food intake it was observed megaphagia (the use, great quantity of food) and was hypersexuality. Such condition repeated every 30-40 days and lasted 10 days. Out of an episode of an excessive sleep, any infringements from outside mentalities, including, cognitive disturbances and behavioral problems were not observed. And each time during a sleep it was observed megaphagia and hypersexuality. Laboratory analyses (the analysis of blood, urine, faeces, hormonal both biochemical and others research) were within norm. Computer and magnetic resonance imaging of a brain without pathology. EEG are characteristic for a night sleep. 